\title{
Bacillary angiomatosis triggered by severe trauma in a healthy Caucasian patient: A case report
}

\author{
MIHAELA BALABAN ${ }^{1,2}$, ROXANA IOANA NEDELCU $^{1,3}$, GABRIELA BALMES $^{4}$, \\ TEODORA ADELA TODOROVIC ${ }^{4}$, ALICE BRINZEA ${ }^{3,5}$, LUCIANA NICHITA ${ }^{6}$, \\ CRISTIANA GABRIELA POPP ${ }^{6}$, RAZVAN THEODOR ANDREI ${ }^{6}$, \\ SABINA ANDRADA ZURAC ${ }^{6}$, DANIELA ADRIANA ION ${ }^{3}$ and GABRIELA TURCU ${ }^{1,4,7}$
}

\begin{abstract}
${ }^{1}$ Department of Dermatology, Derma $360^{\circ}$ Clinic, Bucharest $011273 ;{ }^{2}$ Department of Biochemistry, Faculty of Medicine, Carol Davila University of Medicine and Pharmacy, Bucharest 050474; ${ }^{3}$ Department of Pathophysiology,

Faculty of Medicine, Carol Davila University of Medicine and Pharmacy, Bucharest 020105;

${ }^{4}$ Department of Dermatology, Colentina Clinical Hospital, Bucharest 020125; ${ }^{5}$ Department of Ambulatory, National Institute for Infectious Diseases Prof. Dr. Matei Bals, Bucharest 020105; ${ }^{6}$ Department of Pathology, Colentina Clinical Hospital, Bucharest 020125; ${ }^{7}$ Department of Dermatology, Faculty of Medicine, Carol Davila University of Medicine and Pharmacy, Bucharest 050474, Romania
\end{abstract}

Received October 18, 2019; Accepted November 21, 2019

DOI: $10.3892 /$ etm.2019.8260

\begin{abstract}
Bacillary angiomatosis represents a cutaneous and systemic infection caused by Bartonella species, typically described in the past in HIV-positive patients or associated with immunodeficiencies. More recent case reports had brought into attention the probability that this entity may manifest in otherwise healthy individuals, triggered by trauma and skin burns. The physiopathology of this neoproliferative process is based on the production of angiogenetic molecules, such as vascular endothelial growth factor (VEGF) and IL-8. In case of an inadequate treatment, the evolution can be fatal, with a systemic dissemination of the abscesses within the gastro-intestinal tract, respiratory tract, brain and bones. The appropriate therapy is with oral erythromycin and doxycycline, but several treatments such as cephalosporins, penicillins, macrolides, aminoglycosides, rifampin, dapsone, ciprofloxacin, have been tried with favorable results. Herein we present the case of a Caucasian patient, seronegative for HIV, who developed multiple vascular papules and nodules on the face, after a severe trauma and which healed after an adequate antibiotic therapy with oral clarithromycin.
\end{abstract}

Correspondence to: Dr Roxana Ioana Nedelcu, Department of Pathophysiology, Faculty of Medicine, Carol Davila University of Medicine and Pharmacy, 1 Calistrat Grozovici Street, Bucharest 020105, Romania

E-mail: roxanaioana.nedelcu@yahoo.com

Key words: bacillary angiomatosis, trauma, immunocompetent patient

\section{Introduction}

Bacillary angiomatosis is an angioproliferative cutaneous and extracutaneous disease, caused by infection with the intracellular Gram-negative coccobacillus Bartonella species (Bartonella (B) henselae and Bartonella (B) quintana) (1). The physiopathology of this neoproliferative process is based on the production of angiogenetic molecules, such as vascular endothelial growth factor (VEGF) and IL-8 (1-3).

Cats are the most important reservoir for $B$. henselae and the transmission between cats is realised through a flea vector (Ctenocephalides felis) (4). In immunocompetent patients, the infection with this bacterium can lead to the 'cat scratch disease' (5). In these situations, almost $90 \%$ of patients admit a recent contact with a cat (a scratch or a bite) (4). In both immunodeficient and immunocompetent patients, $B$. henselae can produce bacillary angiomatosis, but in this case, fleas may play a major role in transmitting the infection to humans, considering the fact that only $20 \%$ of patients or less admit exposure to cats $(4,6)$. In order to sustain this hypothesis, $B$. henselae DNA was detected in fleas (7-9).

B. quintana has a human reservoir and among humans it can be transmitted by body lice (Pediculus humanus) and fleas as well, especially in the context of poverty, lack of hygienic conditions and homelessness $(5,10)$. Moreover, it was the causative organism of trench fever among militaries in World War I (11).

\section{Case report}

We present the case of a 43-year-old patient, who had an impressive facial eruption evolving for three weeks, associated with cervical lymphadenopathy. Consent for publication was obtained from the patient. Clinical examination revealed multiple angiomatous erythematous papules and nodules on 


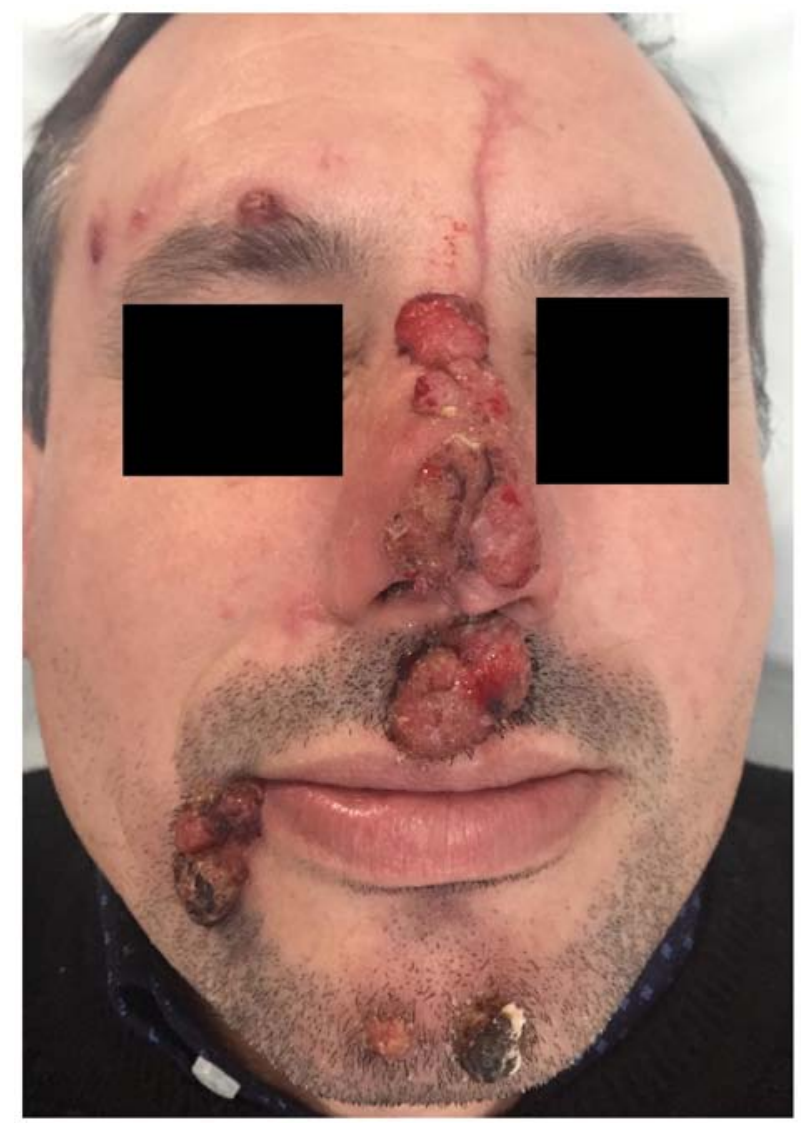

Figure 1. The aspect of the eruption before treatment: angiomatous papules and nodules covered by hematic and honey-like yellowish crusts.

the nasal pyramid, philtrum region, right supraorbital area, mental protuberance and right commissure of the lips, either isolated or grouped, some of them covered by hematic and honey-like yellowish crusts (Fig. 1).

The lesions appeared one week after a severe local trauma produced by a bicycle accident. In the place where the wound on the nose was sutured, the patient noticed red macules that evolved very quickly into papules and nodules, followed by the appearance of other lesions on the face. The oral cavity was normal and he did not have any other complains. He denied any contact with cats or travel in other countries. The clinical aspect of the eruption pointed towards the diagnosis of bacillary angiomatosis.

\section{Results}

The complete blood count, blood chemistry, liver and renal tests, urine analysis and erythrocyte sedimentation rate were within normal values and pulmonary radiography and abdominal ultrasound did not show any anomalies. HIV serology assessed by ELISA was negative, as well as the screening tests for hepatitis B and C. A bacterial culture performed from the lesion showed Staphylococcus aureus colonization.

Histopathological examination revealed in the dermis a diffuse proliferation of small caliber vascular structures, some of them dilated, lined by edematous endothelial cells. The edematous stroma was associated with a

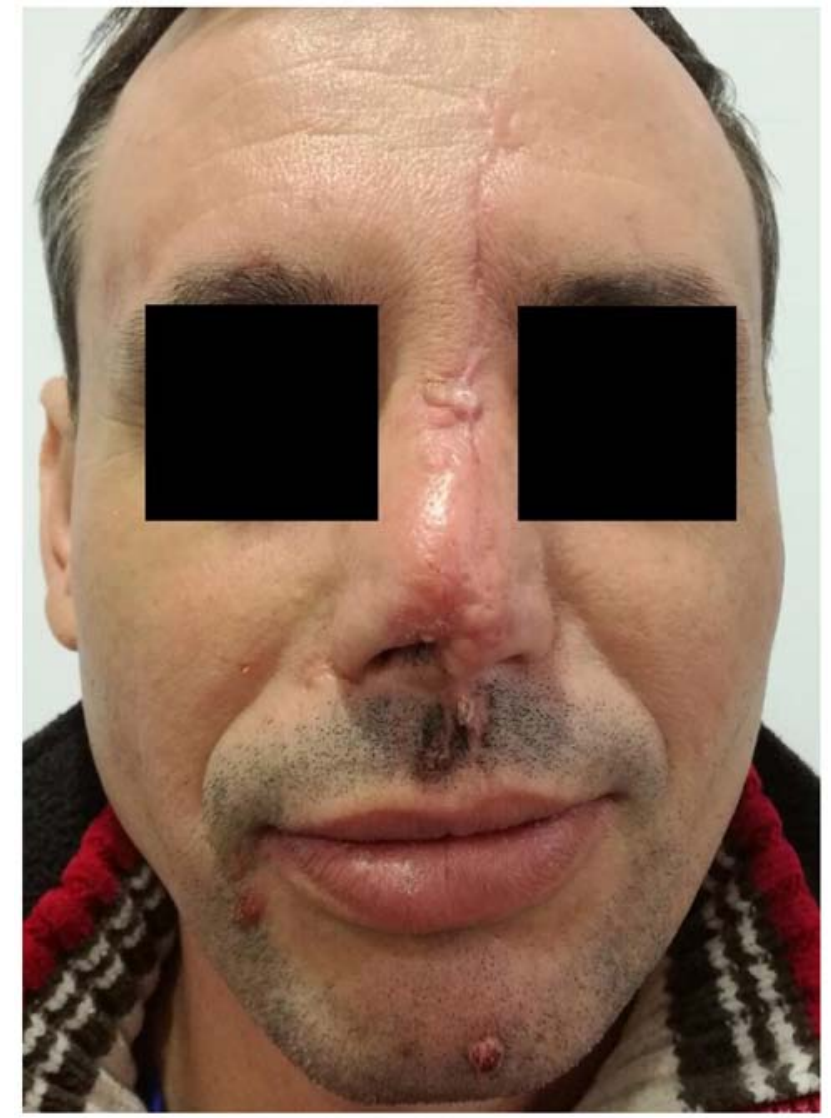

Figure 2. The aspect of the eruption one month after treatment: two remnant papules on the face.

polymorphous inflammatory infiltrate (mostly neutrophils, but also lymphocytes, plasma cells and histiocytes) dispersed throughout the lesion. Moreover, derma-epidermal ulceration was present, with a necrotic detritus with fibrin, leucocytes and small microbial colonies, and positive Giemsa and Warthin Starry stains. The histopathological findings were compatible with pyogenic granuloma/bacillary angiomatosis or verruga peruana. Verruga peruana was excluded because the patient denied traveling in South America. In vivo imaging techniques do not provide much support for the diagnosis, although progress has been made in recent years in some inflammatory skin diseases (12).

The patient was prescribed clarithromycin $500 \mathrm{mg}$ twice daily for six weeks. After the first ten days of treatment, a gradual reduction in size of the lesions was observed. After one month, there were only two remnant papules on the face that were shave biopsied (Fig. 2). Considering the clinical aspect of the lesions, the histopathological findings and the rapid remission after initiation of the antibiotic treatment (which is not characteristic for pyogenic granuloma) a final diagnosis of bacillary angiomatosis was made. In the year of follow-up, there was no recurrence.

\section{Discussion}

Bacillary angiomatosis was first described several decades before in HIV-positive patients (13) as an opportunistic infection, but it may also occur in the context of other conditions that 
may impair the immune status, such as chronic lymphocytic leukemia $(11,14,15)$, chemotherapy (16), systemic corticotherapy (17), solid organ transplantation (18-20), hepatitis B infection (3). Nevertheless, immunocompetent patients can be affected by this cutaneous disorder $(6,17,21-24)$. It can also appear in pediatric patients $(20,24,25)$.

The presented patient was HIV, HBV (hepatitis B virus) and HCV (hepatitis $C$ virus) negative, other causes of immunosuppression were absent and he was not taking any drugs.

Only a case with lesions on the face resembling those of the presented patient was found in the literature, that appeared on the site of a recent burn (6), as well as lesions induced by recent trauma (3). Moreover, a healthy child, without any sign of immunodeficiency, developed bacillary angiomatosis on the face after a traumatic wound, as in the case of the presented patient (24). In these cases, the infection could be transmitted by sandflies, ticks or unknown vehicle (3).

Clinically, the lesions may mimic the aspect of pyogenic granulomas, Kaposi's sarcoma or verruga peruana, described as bright red, purple or violaceous vascular papules and nodules, with sharp demarcation and a chronic evolution over days to months $(7,26,27)$. The surface may be friable, with tendency to bleed or it may be covered by serous and hematic crust (7). More rarely, the clinical picture may be represented by subcutaneous nodules or indurated plaques (26-29). In HIV patients bacillary angiomatosis presents as a large, subcutaneous tumoral mass $(5,30)$. A case of bacillary angiomatosis in an immunocompetent patient, presenting erythematous nodules on the legs which became ulcerated, has been described (27). The eruption usually involves the face, the neck, the trunk and the limbs, but other regions can be affected as well, including the scalp (22). Bacillary angiomatosis can also affect the mucous membranes (tarsal and oral mucosa) (31).

Clinical examination can reveal one single papule or nodule, but hundreds of lesions can also be present (32). In case of inadequate treatment, the evolution can be fatal, with a systemic dissemination of the abscesses within the gastro-intestinal tract, respiratory tract, brain and bones $(5,25,31)$. Fever, weight loss, anorexia, malaise and lymphadenopathy may be associated complaints (31). In case the abscesses invade the liver or the spleen, $B$. henselae can be the first culprit of this disease called 'bacillary peliosis' $(4,19)$.

The histopathological description correlates with the clinical appearance of the lesions. When pyogenic granuloma-like lesions are seen, microscopy shows elements that are more superficially located, characterized by a lobular proliferation of small vascular structures (capillaries and venules) and plump endothelial cells, associated with an inflammatory infiltrate (with neutrophils, lymphocytes and histiocytes) $(18,19,22,26)$. In other clinical forms, the cellular content is more dense and deeper $(22,26)$. The presence of a dense neutrophilic inflammatory infiltrate and granular amphophilic content may point towards bacillary angiomatosis (22). Bartonella spp can not be visualized on conventional hematoxylin-eosin staining, but the granular amphophilic material corresponds with the presence of dark bacilli on silver dye (7). Moreover, microscopy findings may be similar to those of Kaposi's sarcoma, pyogenic granuloma, angiosarcoma, or insect bite (22). However, in contrast with bacillary angiomatosis, endothelial cells in Kaposi's sarcoma are spindle, flattened and, depending on the stage, form dissecting slit-like vascular spaces, and fascicles with variable ery throcyte extravasation (33). Pyogenic granuloma has a lobular architecture, with neutrophils located at the ulcerated surface of the lesion and without identifiable organisms.

In several case presentations, the final diagnosis was based on the demonstration of clustered or solitary bacilli within or around the vessels on Warthin-Starry silver staining in histopathological fragment of the lesion $(6,17,21)$. Other new diagnosis methods for detection of the bacteria, such as tissue culture, serologic tests and molecular methods (detection of DNA Bartonella spp by PCR in the blood or tissue) are available in specialized laboratories $(5,31)$.

Due to financial limitations, in the case of our patient we could not perform DNA detection of Bartonella species by PCR and specific serologic tests. Thereby, the final diagnosis was based on the clinical aspect of the lesions, the histopathological report and the rapid remission after initiation of the antibiotic treatment, which excluded other differential diagnosis.

The appropriate therapy is with oral erythromycin (500 mg x4/daily) and doxycycline (100 mg twice daily), but several treatments such as cephalosporins, penicillins, macrolides, aminoglycosides, rifampin, dapsone, ciprofloxacin, have been tried with favorable results $(19,31,34,35)$.

We suggest the importance of further studies regarding treatment strategy in bacillary angiomatosis. There are a small number of published reports, especially in immunocompetent patients. Even if oral erythromycin remains the drug of choice for bacillary angiomatosis, we found some interesting observations: the response to treatment can range from a spectacular and fast one to an incomplete and chronic one; lack of response to erythromycin but adequate response to clarithromycin.

The rapid healing of the eruption in the presented case also suggest the utility of further studies regarding the modulation of endothelial cell proliferation irrespective of the antibacterial potency of the agent used for the treatment. Macrolides interfere with endothelial cells, immune and inflammatory cells. Identifying a drug that optimally combines all these effects may be a goal for other research. Knowing the reported inhibitory effect of clarithromycin on tumor-induced angiogenesis, we also highlight the possible beneficial role of these molecules in the treatment of angioproliferative diseases, with positive or negative infectious etiology.

A consensus regarding the appropriate period of time that the treatment should be prescribed is missing, thereby even though the lesions can disappear within a few days or one-two months, continuing the therapy for three to six months in order to prevent recurrences is the best approach, especially in HIV patients $(7,19,31)$.

In conclusion, the presented case was unique in that the patient was seronegative for HIV and exhibited extensive lesions on the face, after local trauma that remitted rapidly with antibiotic treatment. 


\section{Acknowledgements}

Not applicable.

\section{Funding}

This work is supported by grants of Ministery of Research and Innovation, CNCS-UEFISCDI, project number PN-III-P4-ID-PCE-2016-0641, within PNCDI III and CCCDI-UEFISCDI, project number 61PCCDI/2018 PN-III-P1-1.2-PCCDI-2017-0341, within PNCDI-III.

\section{Availability of data and materials}

All patient data are mentioned in the article and are available from the corresponding author on resonable request.

\section{Authors' contributions}

MB, RIN, GB, TAT, AB, DAI and GT had substantial contributions to the conception of the work and the acquisition of data for the work. LN, CGP, SAZ and RTA had substantial contributions to the analysis and interpretation of data for the work. All the authors were involved in writing the manuscript and revised the manuscript critically for important intellectual content, approved the final version to be published and agreed to be accountable for all aspects of the work in ensuring that questions related to the accuracy or integrity of any part of the work are resolved.

\section{Ethics approval and consent to participate}

Patient consent to participate was obtained before publication.

\section{Patient consent for publication}

Patient consent for the images was obtained before publication.

\section{Competing interests}

The authors declare that they have no competing interests.

\section{References}

1. Blattner C, Jacobson-Dunlop E, Miller JH and Elston DM: A case of bacillary angiomatosis in a patient with pancreatic adenocarcinoma. J Cutan Pathol 41: 277-280, 2014

2. Sommer LL, Reboli AC and Heyman WR: Bacterial diseases. In: Dermatology. Bolognia JL, Schaffer JV and Cerroni L (eds) 4th edition. Elsevier, USA, pp1282-1285, 2017.

3. Kaçar N, Taşli L, Demirkan N, Ergin C and Ergin S: HIV-negative case of bacillary angiomatosis with chronic hepatitis B J Dermatol 37: 722-725, 2010.

4. Millet CR, Halpern AV, Reboli AC and Heymann WR: Bacterial diseases. In: Dermatology. Bolognia JL, Jorizzo JL and Schaffer JV (eds). 3rd edition. Elsevier Saunders, USA, pp1208-1210, 2012.

5. Markowicz M, Käser S, Müller A, Lang G, Lang S, Mayerhöfer M, Stanek $\mathrm{G}$ and Rieger A: Bacillary angiomatosis presenting with facial tumor and multiple abscesses: A case report. Medicine (Baltimore) 95: e4155, 2016.

6. Karakas, M. Baba, VAksungur VL, Homan S, Memisoglu HR and Uguz A: Bacillary angiomatosis on a region of burned skin in a immunocompetent patient. Br J Dermatol 143: 609-611, 2000.
7. Nosal JM: Bacillary angiomatosis, cat-scratch disease, and bartonellosis: What's the connection? Int J Dermatol 36: 405-411, 1997.

8. Zangwill KM, Hamilton DH, Perkins BA, Regnery RL, Plikaytis BD, Hadler JL, Cartter ML and Wenger JD: Cat scratch disease in Connecticut. Epidemiology, risk factors, and evaluation of a new diagnostic test. N Engl J Med 329: 8-13, 1993.

9. Chomel BB, Kasten RW, Floyd-Hawkins K, Chi B, Yamamoto K, Roberts-Wilson J, Gurfield AN, Abbott RC, Pedersen NC and Koehler JE. Experimental transmission of Bartonella henselae by the cat flea. J Clin Microbiol 34: 1952-1956, 1996.

10. Foucault C, Brouqui P and Raoult D: Bartonella quintana characteristics and clinical management. Emerg Infect Dis 12: 217-223, 2006

11. Fulchini R, Bloemberg $\mathrm{G}$ and Boggian K: Bacillary angiomatosis and bacteremia due to Bartonella quintana in a patient with chronic lymphocytic leukemia. Case Rep Infect Dis 2013: 694765, 2013.

12. Căruntu C, Boda D, Căruntu A, Rotaru M, Baderca F and Zurac S: In vivo imaging techniques for psoriatic lesions. Rom J Morphol Embryol 55 (Suppl): 1191-1196, 2014.

13. Stoler MH, Bonfiglio AT, Steigbigel RT and Pereira M: An atypical subcutaneous infection associated with acquired immune deficiency syndrome. Am J Clin Pathol 80: 714-718, 1983.

14. Török L, Virágh SZ, Borka I and Tápai M: Bacillary angiomatosis in a patient with lymphocytic leukaemia. Br J Dermatol 130: 665-668, 1994

15. Milde P, Brunner M, Borchard F, Südhoff T, Burk M, Zumdick M, Goerz G and Ruzicka T: Cutaneous bacillary angiomatosis in a patient with chronic lymphocytic leukemia. Arch Dermatol 131: 933-936, 1995.

16. Myers SA, Prose NS, Garcia JA, Wilson KH, Dunsmore KP and Kamino H: Bacillary angiomatosis in a child undergoing chemotherapy. J Pediatr 121: 574-578, 1992.

17. Schwartz RA, Gallardo MA, Kapila R, Gascón P, Herscu J, Siegel I and Lambert WC: Bacillary angiomatosis in an HIV seronegative patient on systemic steroid therapy. Br J Dermatol 135: 982-987, 1996.

18. Moulin C, Kanitakis J, Ranchin B, Chauvet C, Gillet Y, Morelon E and Euvrard S: Cutaneous bacillary angiomatosis in renal transplant recipients: report of three new cases and literature review. Transpl Infect Dis 14: 403-409, 2012.

19. Orsag J, Flodr P, Melter O, Tkadlec J, Sternbersky J, Hruby M, Klicova A, Zamboch K, Krejci K and Zadrazil J: Cutaneous bacillary angiomatosis due to Bartonella quintana in a renal transplant recipient. Transpl Int 28: 626-631, 2015.

20. Rostad CA, McElroy AK, Hilinski JA, Thompson MP, Drew CP, Denison AM, Zaki SR, Mahle WT, Rogers J, Abramowsky CR, et al: Bartonella henselae-mediated disease in solid organ transplant recipients: two pediatric cases and a literature review. Transpl Infect Dis 14: E71-E81, 2012.

21. Schwartz RA, Nychay SG, Janniger CK and Lambert WC: Bacillary angiomatosis: Presentation of six patients, some with unusual features. Br J Dermatol 136: 60-65, 1997.

22. Kayaselçuk F, Ceken I, Bircan S and Tuncer I: Bacillary angiomatosis of the scalp in a human immunodeficiency virus-negative patient. J Eur Acad Dermatol Venereol 16: 612-614, 2002.

23. Zarraga M, Rosen L and Herschthal D: Bacillary angiomatosis in an immunocompetent child: A case report and review of the literature. Am J Dermatopathol 33: 513-515, 2011.

24. Turgut M, Alabaz D, Karakas M, Kavak M, Aksaray N, Alhan E, Cevlik $\mathrm{F}$ and Tuncer I: Bacillary angiomatosis in an immunocompetent child with a grafted traumatic wound. J Dermatol 31: 844-847, 2004

25. Rodriguez O, Campbell LR, Bacha JM and Kovarik CL: Successful treatment of bacillary angiomatosis with oral doxycycline in an HIV-infected child with skin lesions mimicking Kaposi sarcoma. JAAD Case Rep 2: 77-79, 2016.

26. Webster GF, Cockerell CJ and Friedman-Kien AE: The clinical spectrum of bacillary angiomatosis. Br J Dermatol 126: 535-541, 1992.

27. Karakaş M, Baba M, Homan S, Akman A, Acar MA, Memişoğlu HR and Gümürdülü D: A case of bacillary angiomatosis presenting as leg ulcers. J Eur Acad Dermatol Venereol 17: 65-67, 2003.

28. Sala M, Font B, Sanfeliu I, Quesada M, Ponts I and Segura F: Bacillary angiomatosis caused by Bartonella quintana. Ann NY Acad Sci 1063: 302-307, 2005. 
29. Schlüpen EM, Schirren CG, Hoegl L, Schaller $M$ and Volkenandt M: Molecular diagnosis of deep nodular bacillary angiomatosis and monitoring of therapeutic success. Br J Dermatol 136: 747-751, 1997.

30. Wanat KA, Reid E, Kamiyango W, El-Mallawany NK and Kovarik CL: Tumoral bacillary angiomatosis in a child with human immunodeficiency virus. JAMA Dermatol 150: 1015-1016, 2014

31. Lopes L, Borges-Costa J, Janeiro N, Neves D, Soares AlmeidaL and Filipe P: Bacillary angiomatosis in a HIV-positive patient with poor adherence to antiretroviral therapy. Acta Dermatovenerol Croat 22: 294-297, 2014.
32. Mejía F and Seas C: Images in clinical tropical medicine: Bacillary angiomatosis. Am J Trop Med Hyg 91: 439, 2014.

33. Grayson W and Pantanowitz L: Histological variants of cutaneous Kaposi sarcoma. Diagn Pathol 3: 31, 2008.

34. Rolain JM, Brouqui P, Koehler JE, Maguina C, Dolan MJ and Raoult D: Recommendations for treatment of human infections caused by Bartonella species. Antimicrob Agents Chemother 48: 1921-1933, 2004

35. Prutsky G, Domecq JP, Mori L, Bebko S, Matzumura M, Sabouni A, Shahrour A, Erwin PJ, Boyce TG, Montori VM, et al: Treatment outcomes of human bartonellosis: A systematic review and meta-analysis. Int J Infect Dis 17: e811-e819, 2013. 